\title{
“HORROR SUBJECTIVI"
}

\section{(A POLEMICA ENTRE KERRY E FREGE EM TORNO AO MÉTODO PSICOLÓGICO)}

Horror subjectivi (the polemic between Kerry and Frege about the psychological method)

Mario Ariel González Porta *

Resumo: A disputa com Kerry é mais um momento na polêmica de Frege com o psicologismo. Considerá-la contribui com elementos essenciais para compreender melhor o papel de Frege na mencionada polemica, assim como a peculiaridade de sua posição.

Palavras chaves: Psicologismo, método psicológico, principio de imanência, Frege, Kerry.

Abstract: The dispute with Kerry is another moment of Frege's polemic concerning psychologism. Taking it into account widely contributes to a better understanding of Frege's role in the aforementioned polemic and the particularities of his position.

Key-words: Psychologism, psychological method, principle of immanence, Frege and Kerry.

\footnotetext{
* Departamento de Filosofia da Pontifícia Universidade Católica de São Paulo. Artigo submetido a avaliação no dia 18/03/2012 e aprovado para publicação no dia 03/01/2013.
} 


\section{Introdução}

$\mathrm{P}$ ara a maioria dos estudiosos de Frege, o nome Kerry significa somente aquele obscuro autor, com o qual Frege se confronta em "Sobre Conceito e Objeto" e cujas confusões refuta de modo definitivo. A isto se acresce que a discussão de Frege com Kerry é considerada somente em seu significado formal. Desta forma, não se dá atenção nem ao contexto da mesma como um todo; ainda menos a quem, de fato, foi Kerry. A discussão com Kerry, não obstante, é um momento decisivo do combate de Frege ao psicologismo e deve ser considerada neste marco.

\section{Aspectos gerais sobre a vida e obra de Kerry ${ }^{1}$}

Kerry iniciou sua carreira como assistente do neokantiano Windelband, para depois se aproximar de Brentano. Isso significa que ele passou do método transcendental para o psicológico, do antipsicologismo à ênfase na necessidade de uma fundamentação do conhecimento pela análise psicológica (IV, 249). A tarefa que Kerry adota para si é a de aplicar o método psicológico de Brentano a uma fundamentação da aritmética.

Dado que, na sua opinião, a própria alternativa intuicionismo-logicismo é incompleta, ele se opõe tanto a um quanto ao outro. Os números não podem ser fundamentados nem em conceitos, nem em intuições. Não é possível fornecer uma fundamentação dos números em conceitos, pois, neste caso, enquanto não se prove que há objetos que correspondem aos mesmos, as verdades matemáticas não passam de meras construções hipotéticas. Números não são, no entanto, tampouco dados na intuição, seja esta pura ou empírica. Com base no que acaba de ser dito, coloca-se a pergunta: então como eles são dados? ${ }^{2}$ Para fornecer uma resposta a esta pergunta, Kerry constrói sua teoria do "trabalho psíquico" (psychische Arbeit), a qual intenta explicar como objetos, que não são dados na intuição, são, não obstante, dados através de atividades da consciência (Bewusstseinstätigkeiten). "Trabalho psíquico" é todo "ato" que podemos

\footnotetext{
${ }^{1}$ Veja-se a este respeito as importantes contribuições de Picardi e Peckhaus indicadas na bibliografia.

${ }^{2}$ È sabido que esta foi uma pergunta de Frege em GA. Por tal razão, é interessante verificar como dita pergunta é tratada sob uma perspectiva semântica e sob uma perspectiva psicológica. 3 "Es ist gezeigt worden, dass diejenigen Sätze der Arithmetik, auf welche wir uns im vorangehenden Artikel beschränkt haben, d.i. die Sätze über Anzahlen, absolute ganze Zahlen, nicht auf Anschauung beruhte: sie liessen sich vollkommen aus den in sie eintretenden Begriffe ableiten. Freilich besassen sie, solange die Realität dieser Begriffe dahingestellt blieb, nur hypothetischen Charakter. Aber auch der Nachweis dieser Realität beruhte nicht auf Anschauung - wenn man mit diesem Terminus den Sinn verband, den wir damit ver-
} 
executar de modo voluntario, aproximando-se este conceito ao husserliano de "síntese ativa" (aktive Synthese). Em ambos os casos trata-se de um desenvolvimento a partir do conceito estático-passivo de intencionalidade de Brentano, que estabelece um pressuposto fundamental para a "teoria da constituição" (Konstituitionstheorie). ${ }^{4}$

\section{As criticas de Kerry a Frege}

Sobre a base das ideias reitoras anteriormente descritas, Kerry dirige quatro críticas a Frege.

a. A primeira é bem conhecida e diz respeito à diferença entre conceito e objeto. É de se ter em conta, no entanto, que ela é uma consequência da oposição entre abordagem psicológica e lógica. Na perspectiva psicologista a diferença entre conteúdo (Inhalt) e objeto (Gegenstand) só pode ser relativa, dado que, em princípio, toda representação deve poder ser objeto de outra representação. ${ }^{5} \mathrm{Na}$ perspectiva lógica-objetivista de Frege, pelo contrario, isto é um total absurdo: a mencionada diferença é categorial e absoluta.

b. Segundo Kerry, Frege trabalha com um conceito de lógica que não determina de modo adequado (IV, 261). ${ }^{6}$ A este, Kerry opõe um conceito

bunden wissen wollten -, sondern auf unserem Bewusstsein gewisse psychische Arbeiten vollziehen zu können." (IV, 249)

"Dass die Arithmetik der Anschauung bedürfe, wenn sie nicht als „rein logischer Natur" sich erweist, ist solange nicht zuzugeben, als man an unserem Begriffe der "Anschauung" festhält. Die Disjunktion: entweder rein logisch oder "räumlichen Anschauung“ resp. der „physikalische Beobachtung“ bedürftig ist unvollständig: sie wäre auch dann noch unvollständig, wenn man als Disjunktionsglieder die zeitliche Anschauung oder die Anschauung der Zeichen hinzunähme. Außer dem Anschaulichen einerseits und denjenigen Vorstellungen und Urtheilen, wie sie die Logik in sich birgt andererseits sind es die Formen psychischer Arbeit überhaupt, welche den Gegenstand wissenschaftlicher Behandlung abgeben können; die innere Wahrnehmung (deren Begriff verschieden ist von dem der Anschauung), lehrt sie kennen, wie sie auch diejenigen Vorstellungen und Urteile kennen lehrt, welche den Gegenstand der Logik abgeben." (IV,305)

${ }^{4}$ Mais a respeito adiante (5.3.).

${ }^{5}$ Considerações semelhantes se encontram em Twardowsky e Marty. Ver do autor „Un análisis del opúsculo de Kasimir Twardowsky „Inhalt und Gegenstand"”.

6 "An diese und frühere Erklärungen F.'s muss sofort die Frage geknüpft werden, worin denn die "rein logische Natur" einer Schlussweise bestehe? Würde es sich hier nur um die einer solchen Schlussweise zu Grunde liegenden Urtheile handeln, so könnte man sich die Auskunft geben: diese Urteile seien jene evidenten Sätze, welche das Analytisch-Sein eines Urteiles begründen. Da es sich aber bei F. auch um die Logifizierung von Vorstellungen handelt (man denke z.B. an einem allgemeinen Begriff der Anzahl), so muss ihm ein weitergehender Begriff des Logischen vorschweben, der hätte angegeben werden sollen. Eine solche Angabe wäre um so wichtiger, als erst vermöge derselben Klarheit darüber verbreitet würde, ob mit 
de lógica fundado na psicologia descritiva brentaniana e que consiste primariamente em sublinhar a diferença entre ato e conteúdo. Com o ato ocupa-se a psicologia, com o conteúdo, a lógica. A ferramenta do conhecimento lógico é, por outra parte, a percepção interna.

c. Frege apela em GA à Razão como faculdade de apreensão do objetivo não real (GA, 41-42). Kerry critica essa colocação, a qual para ele não representa outra coisa que um "hipostasiar uma faculdade totalmente inarticulada (ungegliedert) como fundamento da objetividade", algo que não acompanha a situação da pesquisa psicológica da época e nem sequer faz jus ao estado da questão no próprio Kant. ${ }^{7}$ Kerry exige, pois, uma análise intencional diferenciada.

d. A anterior objeção é meramente um aspecto de outra, mais abrangente e que estabelece uma recusa de princípio do combate antipsicologista fregeano. Por ser central ao nosso interesse atual, nos ocuparemos detidamente com ela na próxima seção.

\section{A rejeição da critica de Frege ao psicologismo}

Para simplificar a exposição que ofereceremos nesta seção, citaremos isoladamente o texto decisivo e dividi-lo-emos em três momentos que não seguem exatamente a ordem do mesmo:

“ [1.a] Nesta concepção, tampouco há razão para temer que a aritmética se torne uma ciência do subjetivo, uma psicologia. [2.a] Muito mais fecundo

der Zurückführung des Arithmetischen auf das Logische, wirklich eine tiefere Begründung der ersteren erreicht werde". (IV, 261) É muito provável que Frege nunca esperou uma tal crítica no sentido de colocar seu programa em questão por não possuir um conceito de lógica preciso. Por certo, isto não permanecerá sem consequências em Frege.

7 „Man weiß, wie ernst z.B. Kant diese Aufgabe [a de clarificar o surgimento do objetivo a partir do subjetivo (M.A.G.P.)] genommen hat. Zwar ist seine Unterscheidung zwischen „Wahrnehmungs-“ und „Erfahrungsurteil“"... nicht für einwurfsfrei zu halten, jedenfalls war aber auch schon Kant darüber hinaus, ein ganz ungegliedertes Vermögen der "Vernunft" als Grund der Objektivität zu hipostasieren, und damit, dass er die Anzahlen als Vernunftgegenstände hinstelle, die allgemeine Anerkennung der arithmetischen Sätze verbürgen zu wollen. Geschweige, dass die heutige Psychologie mit einer solchen Auskunft vorliebnehmen dürfte... so dürfen hiermit einige Momente angegeben sein, welche eine lichtvollere Erklärung ihrer objektiven Gültigkeit anzubahnen im Stand sind, als die bloße Berufung auf die "Vernunft" zu bieten vermag." (IV, 305-307) Seja notado de passagem que precisamente a crítica da psicologia de Kant, isto é, da assumpção irreflexiva da psicologia das faculdades (Vermögenspsychologie), jogou um papel decisivo nos primórdios do psicologismo. Já em Fries e Benecke esteve em primeiro plano a necessidade de substituir a "mitologia“ kantiana por uma "psicologia empírica", o que configura uma tendência que se estenderá até as lições husserlianas sobre Kant. 
[1.b] que ostentar um horror subjectivi [2.b] é observar como, a partir do subjetivo, [3] no qual de qualquer modo nosso conhecimento se inicia, [2.c] poderia provir uma validade objetiva" ${ }^{\prime 8}$

\subsection{O combate de Frege ao psicologismo é infundado}

O texto 1.a - 1.b expõe o mesmo estado de coisas em duas perspectivas:

1.a. Uma fundamentação psicológica da lógica não implica necessariamente o perigo do subjetivismo.

1.b. O radical combate de Frege ao psicologismo é, pois, infundado. Frege padece de horror subjectivi.

Consideraremos o texto sob estas duas perspectivas.

1.a. Se explicitamos o que está implícito no texto, a primeira parte reza: no caso de uma fundamentação psicológica da lógica (ou da aritmética) ${ }^{9}$ "não há razão... para temer que a aritmética se torne uma ciência do subjetivo, ou seja, psicologia". Dito de outra forma: não há razão para temer que uma fundamentação psicológica da lógica/matemática (isto é, a fundamentação da lógica/matemática pelo "método psicológico") conduza ao subjetivismo (isto é, que se subjetive a lógica/matemática, ou seja, faça-se delas uma ciência do subjetivo) ou que a lógica/aritmética se tornem psicologia (isto é, que se ponha em perigo sua objetividade, fazendo dos números algo subjetivo, psíquico).

Em princípio parece claro que, se se toma como referência o conceito rigoroso de objetividade absoluta de Frege, Kerry deveria ser considerado "subjetivista" e não é evidente em que medida ele pode razoavelmente pretender evitar tal acusação. Mas aqui há um ponto importante, que não se pode passar por alto. Sabidamente, Brentano é um dos mais expressivos defensores do "método psicológico", (que caracteriza uma vasta tendência da filosofia alemã do século XIX), consistindo o seu aporte em desenvolver o mesmo no marco de uma concepção intencionalista. Com certeza, muitos defensores do método psicológico eram relativistas e queriam sê-lo. Mas este não era o caso de Brentano, que reagiu energicamente à acusação de "psicologista" por parte de alguns de seus discípulos, negando expressa-

\footnotetext{
8 "[1.a] Bei dieser Auffassung ist auch nicht zu befürchten, dass die Arithmetik zu einer Wissenschaft vom „Subjektiven“, zur Psychologie werde. [2.a] Viel fruchtbarer [1.b] als das Zur-Schau-Tragen eines horror subjectivi [2.b], ist es, zuzusehen, wie aus dem "Subjectiven", [3] wovon doch jedenfalls unser Erkennen seinen Ausgang nimmt, [2.c] ein objektiv Gültiges hervorgehen könne." (IV, 305)

9 Já que a questão se relaciona igualmente à lógica e à aritmética, falarei sem mais de „lógica/aritmética".
} 
mente que sua filosofia implicasse em algum sentido o relativismo. ${ }^{10}$ Dado o contexto anterior, não é estranho, que Kerry não se desse ao trabalho de explicar como e por que a sua posição não contém o perigo do subjetivismo. Aparentemente, para ele isto é evidente por si e não merece consideração específica alguma.

1.b. Se Kerry estivesse correto, seguir-se-ia então a inevitável consequência: Frege alerta contra um perigo que não existe. Por conseguinte, seu anti-psicologismo radical deve ser sem mais ironicamente desqualificado como "horror subjectivi".

\subsection{O verdadeiro problema que Frege ignora}

Mas se, segundo a opinião de Kerry, Frege, com sua rigorosa divisão entre lógica e psicologia, vê, por um lado, um problema que de fato não existe, por outro, não vê a verdadeira dificuldade que se torna inevitável neste contexto, a saber, como pode surgir validade objetiva a partir do subjetivo. A isto referem-se as partes 2.a., 2.b e 2.c. do texto: "Muito mais fecundo... é observar como, a partir do subjetivo... poderia provir uma validade objetiva."

Para entender o real sentido da objeção de Kerry, notemos que se deve distinguir aqui entre duas possíveis perguntas, dentre as quais a primeira não contém nenhuma objeção séria, a segunda sim.

a. A primeira pergunta diz respeito à relação entre o subjetivo e o objetivo em geral. A situação seria a seguinte: enquanto Frege simplesmente insiste na estrita distinção entre o subjetivo e o objetivo, Kerry exige dele a clarificação da relação positiva entre ambos. A exigência seria, portanto, a de uma complementação de uma perspectiva unilateral. Para fundamentar a objetividade da matemática é insuficiente permanecer na mera separação absoluta do subjetivo e objetivo, não se podendo prescindir de dar conta da relação positiva entre ambos, pois se deve reconhecer que, de alguma forma, o subjetivo "alcança" (erreicht) o objetivo. De outro modo não teria sentido algum que se pretenda falar dele.

\footnotetext{
${ }^{10} \mathrm{O}$ fato mencionado está em relação a outro, não menos interessante. Quando se fala de "psicologismo", pensa-se em primeiro lugar em autores como Lipps, Sigwart, Wundt e Erdmann, eventualmente, também em Fries e Beneke. Todos eles poderiam valer como psicologistas no sentido de relativistas (uns mais, outros menos e não sem precisões). Ora, em tal caso, deixa-se fora de consideração a escola de Brentano. Ela é sempre lembrada como defensora do método psicológico, mas raramente como parte do movimento psicologista. Por tal razão, seria desejável uma pesquisa minuciosa que fixasse o papel da mesma na polêmica do psicologismo. Seja dito de passagem, é ainda menos conhecido que Husserl mesmo, enquanto identifica psicologia fenomenológica e filosofia transcendental, abandona em „Krise“ a igualação de psicologismo e relativismo.
} 
b. Mas Kerry não exige de Frege meramente uma complementação de sua posição, uma complementação que Frege poderia fornecer, se assim lhe fosse proposto. Pelo contrário, Kerry quer apontar para uma dificuldade de princípio na tese de seu oponente, uma dificuldade que ele só poderia superar se abandonasse seu ponto de partida. Dado que Frege, e pese todo seu "objetivismo", não pode evitar responder a pergunta pela apreensão do objetivo, esta deveria levá-lo então à negação de sua tese, a saber, que se deve separar o mais radicalmente possível o objetivo e o subjetivo ou, dito de outro modo, que se deve fundamentar a objetividade da matemática sem qualquer consideração psicológica.

Kerry não quer assinalar uma mera ausência no pensamento de Frege, senão que para ele se trata de compreender que o que falta em Frege é algo essencial, que não pode faltar e que, se não faltasse, tornaria evidente que a simples insistência no objetivo não leva a nada. A recusa a qualquer "interferência da psicologia na lógica" ${ }^{11}$ é absolutamente insustentável. O único meio de fundamentação é o psicológico, o qual consiste em dar conta de como algo objetivo pode surgir a partir do subjetivo. Esta pergunta não pode ser evitada. Querer adotar uma via puramente objetiva não conduz a lugar nenhum.

Certamente, para um leitor desprevenido, não é em princípio evidente, que a linha de pensamento de Kerry seja de qualquer modo conclusiva. Para que se torne tal, deve-se atentar ao importante trecho 3. ( "...do qual de qualquer forma toma seu início nosso conhecimento...").

\subsection{O princípio de imanência como pressuposição fundamental de toda a objeção}

Kerry argumenta que ainda quando se separe psicologia e lógica e se sublinhe o objetivo tanto quanto se quiser, não obstante, o subjetivo em ultima instância, não se deixa eliminar, dado que todo conhecer necessariamente parte de um sujeito. ${ }^{12}$ Formulado de outra forma:

a. O conhecer parte necessariamente do subjetivo.

b. Segue-se disto que não se pode evitar a explicação de como o objetivo surge do subjetivo.

c. Por tal razão, de maneira alguma é possível contentar-se com uma simples separação entre o subjetivo e o objetivo

${ }_{11}^{11}, .$. Einbruch der Psychologie in die Logik..." (GGA,XIV)

${ }^{12}$ Compare-se o prefácio de Husserl às "Investigações lógicas". 
d. (e isto significa, neste contexto, persistir em uma simples separação entre lógica/matemática e psicologia),

e. mas deve-se, necessariamente, em última instância, recorrer ao método psicológico.

O raciocínio todo se constrói, pois, sob a premissa "a", que não é provada, senão simplesmente pressuposta como evidente. Se esta é concedida, então a argumentação de Kerry é conclusiva; se não o é, ela se torna incompreensível.

Nós devemos explicitar o sentido da premissa. Para isto notamos, em primeiro lugar, que a oposição subjetivo-objetivo, que Kerry retoma de Frege e com a qual trabalha, é equivalente à oposição imanente-transcendente. Se formulamos a tese de Kerry com base nesta última oposição, torna-se então mais claro o que, em última instância, está em jogo, a saber, o "princípio de imanência". ${ }^{13}$

Uma vez que o princípio de imanência é evidenciado como pressuposição fundamental de Kerry, podemos então reconstruir seu argumento da seguinte forma:

a. Nossos únicos objetos imediatos são os conteúdos de nossa consciência, ou seja, nossas representações.

b. Por isto, a única transcendência sobre a qual pode-se com sentido falar, é a que pode ser alcançada a partir da imanência.

c. Portanto, se se quer falar sobre a transcendência, deve-se primeiramente explicar como ela é dada a partir da imanência.

d. Isto, sem dúvida, é impossível sem o recurso ao método psicológico.

e. Em consequência, a mera insistência radical na separação de transcendência e imanência passa por alto o verdadeiro problema.

\section{A reação de Frege à crítica de Kerry}

Uma vez mostrado que a crítica de Frege ao psicologismo enfrentou reações, coloca-se inevitavelmente a pergunta: em que medida ele as tomou em consideração? Para responder a esta pergunta, procederemos em três passos.

\footnotetext{
${ }^{13}$ Por "princípio de imanência“ entendo a tese lockeana expressa, que retoma um tese fundamental de Descartes e caracterizou o pensamento moderno como um todo, de que nossos únicos objetos imediatos são nossas "representações" (Vorstellungen, ideas), ou seja, os conteúdos imanentes de nossa consciência.
} 


\subsection{O combate ao psicologismo como pano de fundo}

Um contra-argumento à tese de que Frege tenha reagido à crítica de Kerry por nós mencionada, seria que ele toma posição explícita com respeito às objeções de Kerry somente no tocante à diferenciação conceito-objeto. Se trouxemos esta discussão em conexão à pergunta do psicologismo, isto ocorreu até o presente momento somente porque nos baseamos no texto do Kerry. Por isso devemos ainda tornar manifesto que o problema do psicologismo constitui para o próprio Frege o pano de fundo de toda sua discussão com Kerry sobre conceito e objeto.

É sabido que Frege estabelece três princípios em GA, dos quais agora nos interessa somente o primeiro e o terceiro:

1. “...separar rigorosamente o psicológico do lógico, o subjetivo do objetivo..." 14

3. “... não perder de vista a diferença entre conceito e objeto..."15

Neste momento Frege deixa ambos os princípios sem relação um ao outro. Isto se altera em "Conceito e objeto", onde ele se refere de modo indireto à relação de ambos. Ali escreve: "E isto me parece tanto mais necessário, quanto suas objeções [de Kerry (MAGP)] repousam, em todo caso, em uma errônea compreensão de minhas colocações sobre o conceito..."16 e, repetindo o já afirmado em GA, imediatamente nota: "A palavra "conceito" é utilizada em sentidos diferentes, em parte em um sentido psicológico, em parte em um lógico, em parte talvez em uma obscura mistura de ambos...". Kerry "confunde, portanto, seu próprio modo de utilização com o meu...". ${ }^{17}$ Finalmente coloca-se em evidência a relação entre a questão do psicologismo e a diferenciação entre conceito e objeto no prefácio de GGA. O contexto no qual a crítica do psicologismo é introduzida nesta obra é o de uma análise da origem última da resistência contra a qual deve lutar a nova lógica da "Conceitografia". Esta origem encontra-se na interferência da psicologia na lógica, devido à qual se negam as distinções essenciais que esta nova lógica introduz e, contrariamente, se exigem outras irrelevantes para a mesma. Dentre estas Frege menciona expressamente a de predicado de primeira e segunda ordem, a de característica e propriedade e, não por fim, a de conceito e objeto (GGA,XIV, XXIV).

\footnotetext{
14 ,...es ist das Psychologische von dem Logischen, das Subjektive von dem Objektiven scharf zu trennen..." (GA, p. 10)

15 „....der Unterschied zwischen Begriff und Gegenstand [é (MAGP)] im Auge zu behalten..." (GA, p. 10)

${ }^{16}$ „Um so nötiger scheint mir das zu sein, als sein [de Kerry (MAGP)] Widerspruch zum Teil jedenfalls auf einem Missverstehen meiner Äusserungen über den Begriff beruht..." (BG,66) ${ }_{17}$ "Das Wort „Begriff" wird verschieden gebraucht, teils in einem psychologischen, teils in einem logischen Sinne, teils vielleicht in einer unklaren Mischung von beiden." Kerry „vermengt" pois „seine eigene Gebrauchweise des Wortes „Begriffes“ mit meiner...". (BG, 66)
} 
Mas há ainda um segundo e importante nível da análise. Concedido que o contexto da distinção conceito-objeto seja o combate ao psicologismo, se impõe então a pergunta, se Frege respondeu especificamente a este ponto da crítica de Kerry. A este respeito, deve-se observar que Frege nunca se refere a tal crítica de modo expresso, porém o faz talvez de modo implícito. Sem ser mencionado pelo nome, Kerry parece ser onipresente no prefácio de GGA, não menos que em um trecho da "Lógica" de 1897.

\section{2. "Leis fundamentais da aritmética" (Grundgesetze der Arithmetik)}

Backer e Hacker criticaram severamente Frege por este não fornecer em GGA nenhum argumento decisivo contra o psicologismo. ${ }^{18}$ Mas os resultados de Frege devem ser avaliados com respeito ao que ele se propõe e não com respeito a parâmetros que lhe são extrínsecos. Ora, Frege não se coloca em GGA o objetivo de "refutar" o psicologismo, senão de "clarificar" sua própria posição. ${ }^{19}$ Mas por que Frege considera necessário "clarificar" sua posição? A isto vem à memória a crítica de Kerry, segundo a qual Frege não possui um conceito claro de lógica. Frege quer, portanto, "clarificar" seu conceito de lógica e, justamente para isso, o contrapõe à concepção rival, ou seja, à psicologista. ${ }^{20}$

O fato de que Frege se propunha a fazer no prefácio de GGA uma "clarificação da disputa" mostra-se evidente e é totalmente coerente com o modo como o texto procede. De fato, o mesmo é construído regressivamente, isto é, Frege parte do estabelecimento de uma distinção inicial entre as posições em pugna para, então, gradualmente, fixar de modo cada vez mais profundo a origem última do antagonismo.

Reconstruamos rapidamente os passos principais deste procedimento:

a. Frege parte de que as diferentes concepções de lógica/matemática, que ele e seus opositores psicologistas possuem, advêm de uma diferente acepção de "lei lógica".

b. Falando mais concretamente, enquanto para Frege "leis lógicas" são leis do ser-verdadeiro (Wahrsein), para seus opositores são leis do ter-por-verdadeiro (Fürwahrhalten).

c. Esta diferença surge de outra, a saber, o próprio conceito de verdade. Para Frege a verdade é algo objetivo, para o psicologista, pelo contrário, não. Este identifica "verdadeiro" com "ser aceito por todos os homens".

\footnotetext{
${ }^{18}$ Ver bibliografia.

${ }^{19}$ Frege diz expressamente: trata-se da “...clarificação da disputa...” ( „...Klärung des Streites..." (GGA, XXV)).

${ }^{20}$ „Dies mag genügen, um meinen logischen Standpunkt durch den Gegensatz ins helleres Licht zu setzen." (GGA, XXV).
} 
d. Mas, a diferença anterior segue-se de uma ainda mais fundamental. Trata-se não meramente de que se aceite ou se negue o verdadeiro, senão de que se aceite ou se negue em geral o objetivo em si (Objektive an sich).

e. Mas por que o psicologista nega a esfera do objetivo? Ele a nega, em última instância, porque considera tudo o que não é real (wirklich) como subjetivo. O psicologista limita, pois, o objetivo ao real e, como o subjetivo é representação (Vorstellung), o reduz a representações.

f. A esta redução opõe-se Frege na medida em que torna explícito que não é conceitualmente necessário identificar realidade (Wirklichkeit) e objetividade (Objektivität).

g. Até agora poder-se-ia acreditar que o psicologista coloca em questão o objetivo, mas deixa o real intocado. Mas este precisamente não é o caso. O psicologista nega não só a existência do objetivo, senão também nosso acesso direto ao real.

h. Se perguntarmos agora, por que isto acontece, então somos levados a observar que o psicologista, em última instância, parte da tese de que nossos únicos objetos imediatos são nossas representações, ou seja, nossos conteúdos-de-consciência (Bewusstseinsinhalte).

i. Afirmar que nossos únicos objetos imediatos são nossas representações, não é outra coisa senão aderir à tese fundamental do idealismo (epistemológico). O psicologista é, portanto, um idealista.

Do exposto acima torna-se claro que, em GGA, Frege chega, através de um procedimento regressivo, a evidenciar o "idealismo" (e isto quer dizer, de fato, o princípio de imanência) como origem última do psicologismo. Isto é algo novo no seu pensamento, algo no qual há uma diferença decisiva entre a crítica ao psicologismo de GA e GGA. Enquanto em GA a crítica ao psicologismo leva à oposição de objetividade e realidade (cessando portanto no quarto passo), em GGA ela vai além disso e se aprofunda. ${ }^{21}$

Se, por um lado, Frege procede regressivamente ao estabelecer a fonte última da diferença entre sua posição e a de seus opositores, por outro, ele dá muita importância a ressaltar que a última consequência do idealismo é o relativismo. Isto pode parecer estranho para um leitor atual. De fato, à primeira vista se pensaria que um idealista no sentido fregeano necessariamente seria um relativista. Mas, como já verificamos em Brentano, isto não era algo que todo defensor do método psicológico concederia sem mais. Por isso, é um objetivo principal do texto tornar evidente que o relativismo é uma consequência inevitável da aceitação do princípio de imanência.

\footnotetext{
${ }^{21}$ Veja-se „La evolución de la crítica fregueana al psicologismo“ (a ser publicado).
} 
Uma vez que, pela via sistemática e através de uma reconstrução puramente lógico-conceitual, Frege chega à conclusão de que o idealismo encontra-se na base do psicologismo, ele muda seu objetivo e, com isto, também seu modus operandi. Ele procura então tornar evidente que a linha de pensamento descrita não é somente a que está na base do psicologismo de um ponto de vista puramente lógico, mas também aquela na qual de fato se funda o psicologismo. É justamente por isso que Frege toma Erdmann como alvo e o cita pormenorizadamente. Se agora nos perguntamos, por que para Frege é tão importante provar, por meio de generosas citações, que Erdmann efetivamente procede como ele descreve, não necessitamos especular muito acerca da resposta, pois esta é fornecida expressamente por Frege: ele quer mostrar que não luta contra "moinhos-de-vento" (Windmühlen), senão que o perigo, ao qual ele se refere, é um perigo real. ${ }^{22}$ Tal modo de proceder faz todo sentido se se considera que seu pano de fundo é a já mencionada ironia de Kerry, que Frege padece de um "horror subjectivi". Frege quer mostrar, pois, concretamente no caso de Erdmann, que o psicologismo traz inevitavelmente o idealismo e o relativismo consigo.

Mas devemos não só perguntar por que Frege cita Erdmann minuciosamente, mas também, além disso, por que ele escolhe precisamente Erdmann, já que este, na primeira edição de sua "Lógica", nem sequer menciona o filósofo de Jena. Um motivo para a escolha de Erdmann foi com certeza o fato de que seu livro aparecera na mesma época da publicação de GGA, fato este, aliás, ao qual Frege expressamente se refere. ${ }^{23}$ Mas há por certo um motivo mais relevante. Erdmann não interessa a Frege como um caso singular, senão como expressão de uma tendência geral. Trata-se, portanto, da escolha de um exemplo paradigmático, no qual é explicito o que em outros muitos permanece implícito e, isto, tanto no sentido da pressuposição básica (o princípio de imanência), quanto no sentido da última consequência (o relativismo). A escolha de Erdmann é, com efeito, um sinal evidente do que Frege considera que é em ultima instancia essencial no psicologismo.

\section{3. “Lógica" (1897)}

Na "Lógica" de 1897 há um trecho famoso, que há muito é citado como prova irrefutável de que Frege não possui nenhum interesse pela teoria do conhecimento (ou melhor: pela teoria do sujeito) e que ele remete sem mais o tema da apreensão do pensamento (Gedanken) à psicologia. O trecho

\footnotetext{
22 „Doch, um nicht den Schein zu erwecken, als kämpfe ich gegen Windmühlen, will ich an einem bestimmten Buche das unrettbare Versinken in den Idealismus zeigen. Ich wähle dazu die oben erwähnte Logik des Herrn B. Erdmann als eins der neuesten Werke der psychologischen Richtung..." (GGA, XIX)

${ }^{23}$ Ver nota anterior.
} 
mencionado diz sem dúvida isto, mas não só isto. Tirado de seu contexto, produz uma impressão falsa e parcial. Ele é muito mais complicado do que a primeira vista pareceria e contém vários outros elementos, que em geral são passados por alto. Todavia, não forneceremos aqui uma leitura detalhada do trecho integral, mas somente uma referência a alguns elementos que são importantes para nosso atual propósito. ${ }^{24}$

No percurso anterior do texto Frege defendeu a tese de que pensamentos (Gedanken), considerados por ele como os genuínos portadores de verdade e falsidade, não podem ser entidades psíquicas, isto é, não podem ser nem representações, nem conexões de representações. Frege se coloca então uma objeção: se pensamentos não podem ser psíquicos, ao menos se deve admitir que a apreensão dos pensamentos seja algo psíquico ou um "processo anímico" (seelischer Vorgang). ${ }^{25}$

Em primeiro lugar deve-se insistir que, sob uma perspectiva puramente formal, jaz aqui uma séria objeção à posição de Frege, um argumento consistente em referir-se a uma suposta verdade inegável que contradiz o ponto de partida de todo o raciocínio fregeano. Mas, não é tão simples compreender por que é assim. Em princípio, poder-se-ia pensar que não há necessidade de haver uma contradição entre o fato de que pensamentos não sejam psíquicos e que sua apreensão o seja. Com efeito, poder-se-ia pensar que todos, inclusive Frege, devem admitir que a apreensão do pensamento é um processo anímico. Se, todavia, a passagem mencionada deve conter um argumento, é porque se pensa que o fato de que a apreensão do pensamento seja algo psíquico, implica que também o apreendido o deva ser. O que é pressuposto é, pois: o apreender é algo psíquico, e algo não pode ser apreendido, sem igualmente ser ele mesmo algo psíquico. Mas isto não é uma evidência em si. Torna-se evidente, não obstante, se formos mais adiante e aceitarmos que o sujeito só pode apreender o que existe "nele", ou seja, se pressupomos a validade do princípio de imanência.

Se a objeção é colocada desta forma, resulta claro que, na passagem mencionada, não se trata da consideração de uma possibilidade puramente lógica, mas de uma referência implícita. A objeção que Frege se coloca na "Lógica" de 1897 está intimamente relacionada com a aquela que Kerry lhe dirige em 1887. ${ }^{26}$ As similitudes são inegáveis e expressam-se inclusive ao nível literal: Frege diz: "Aber, ...doch..."; Kerry diz: “...doch jedenfalls..."

\footnotetext{
24 Veja-se do autor: „La „Lógica“ fregueana de 1897 y la critica al psicologismo“ (a ser publicado).

${ }^{25}$ A respeito da lei da gravidade tomada como exemplo de pensamento (Gedanke), o opositor imaginário observa: "Aber das Erfassen dieses Gesetzes ist doch ein seelischer Vorgang!" (L(1897), 63-64)

${ }^{26}$ Enquanto em 1897 o inimigo de Frege afirma que a apreensão do pensamento é um processo psíquico, Kerry diz, focando o ponto crucial, que o apreendido deve ser psíquico. O efetivo ponto de partida (a pressuposição do princípio de imanência) é, pois, manifesta e a pergunta que se segue dele, explicita.
} 
Sendo a objeção que Frege se coloca no texto de 1897 basicamente a mesma que Kerry lhe colocara, resulta então ainda mais crucial atentar para o modo como Frege reage à mesma na continuação do texto. Neste sentido são diferenciáveis seis momentos.

a. Que nossa leitura é correta se confirma através do modo pelo qual Frege responde a seu opositor. Com efeito, ele observa que, mesmo que o processo em questão seja psíquico, ele se encontra no limite do psíquico e, isto, porque ali se introduz um elemento, o pensamento (Gedanke), que não é nada psíquico. ${ }^{27}$ À primeira vista poderia parecer que Frege não oferece resposta à objeção, mas tão somente uma asserção tão dogmática quanto a de seu oponente: enquanto este afirma que a apreensão do pensamento é algo psíquico, Frege simplesmente nega que este seja o caso. Esta impressão, porém, é falsa. Com certeza, Frege não quer (nem pode) negar que a apreensão do pensamento seja um processo psíquico. $\mathrm{O}$ que ele nega é o fato de que, porque o processo é psíquico, o apreendido também deva sê-lo. O ponto decisivo aqui é que não porque o pensamento (Gedanke) seja apreendido, ele deve tornar-se psíquico. Portanto, a resposta de Frege consiste em clarificar a pressuposição do opositor em seu caráter próprio para, a seguir, negá-la.

b. Se se põe em evidencia a pressuposição enquanto tal, retira-se o suposto problema, ao qual o opositor poderia apontar. ${ }^{28}$ Isto é o que Frege ressalta na nota de rodapé, onde critica a psicologia de seu tempo, porque esta, enquanto tenta derivar o pensar das representações, aceita sem mais que estas são nossos únicos objetos e, portanto, ignora a verdadeira dificuldade. ${ }^{29}$

c. Corretamente formulado, o problema não consiste em como o pensamento (Gedanke) se produz (hervorbringen), senão em como ele é apreendido (fassen) (L (1897), 37), ou seja, em como se apreende algo transcendente, que não por ser apreendido se torna imanente, senão que permanece tão transcendente quanto o é em si.

d. Portanto, uma vez negada a pressuposição do princípio de imanência, um falso problema é dissolvido, mas um novo é colocado, o qual deve ser entendido como reformulação do núcleo legítimo do anterior. A pergunta falsa diz: como surge o objetivo do subjetivo; a correta: como o subjetivo apreende (fassen) o objetivo. Dita reformulação pode ser entendida como uma reação à crítica de Kerry.

27 “Ja! Aber ein Vorgang, der schon an der Grenze des Seelischen liegt und das deshalb vom rein psychologischen Standpunkte aus, nicht vollkommen wird verstanden werden können, weil etwas wesentlich dabei in Betracht kommt, was nicht mehr im eigentlichen Sinne seelisch ist, der Gedanke..." (L (1897), 64).

${ }^{28}$ Como Kerry de fato o faz.

29 "Die Frage ist in ihrer Schwierigkeit wohl noch kaum erfasst. Meistens begnügt man sich wohl damit, das Denken durch eine Hintertür in das Vorstellen einzuschmugeln, so dass man selbst nicht weiss, wie es eigentlich hinneingekommen ist." (L (1897), 64n.). 
e. Poder-se-ia ainda objetar que a reformulação do problema que Frege opera neste texto não tem nada a ver com Kerry e, isto, devido a que a psicologia referida na nota de rodapé é uma psicologia associacionista e não-intencional. Isto é certo; todavia ignora o ponto essencial, a saber, que se trata aqui de um rechaço ao princípio de imanência enquanto tal, independentemente de se adotar uma psicologia de perspectiva intencional ou associacionista. Dito de outra forma: a diferença entre as concepções de sujeito intencionalista e associacionista pode ser importante e digna de nota sob vários pontos de vista, mas é absolutamente irrelevante no tocante à retidão do argumento principal de Frege, a saber, a negação do princípio de imanência.

f. A pergunta a qual Frege recusa pode ser designada como "pergunta teórico constitutiva" (konstitutionstheoretische Frage). Isto tem sérias consequências que não podemos analisar agora. ${ }^{30}$ Dois pontos sejam, não obstante, explicitados:

f1. Todo o projeto da teoria da constituição (Konstitutionstheorie) pressupõe o princípio de imanência e não pode ser executado sem o mesmo. Se não se concede tal princípio, em qualquer de suas formas, então o mencionado programa perde sentido.

f2. O trabalho de Kerry sobre o número dever ser considerado a pré-história da teoria da constituição.

\subsection{A resenha de Frege a Husserl}

Se se atenta para a crítica de Kerry a Frege, então se pode chegar a uma melhor compreensão da reação de Frege à "Filosofia da Aritmética" (PhA) husserliana e isto porque as duas atitudes são aspectos de um e mesmo contexto. Neste ponto são importantes seis elementos:

a. a PhA de Husserl toma Kerry e Frege como principais interlocutores;

b. ainda que Husserl se distancie de Kerry nesta obra, o faz na perspectiva de uma aceitação de seu programa geral;

c. Husserl segue Kerry não somente em seu objetivo, aplicar o método psicológico na fundamentação da matemática, mas também na execução do projeto de uma teoria da constituição.

d. Se não se pode ignorar a semelhança sistemática entre o projeto de Kerry e o de Husserl, é provavelmente por tal razão que Frege entende ambos como expressão de uma única tendência.

\footnotetext{
${ }^{30}$ Nós o faremos em um estudo específico: „Husserl e Frege“.
} 
e. Isto explica, talvez, a virulenta reação de Frege ao escrito de Husserl. Após a leitura de Kerry, era claro de início para Frege qual devia ser o fim da história.

f. Mesmo se, como é de praxe entre os partidários de Husserl, se censure a crítica de Frege a Husserl pelo fato de não dar conta das nuances e particularidades da posição deste, todavia não se pode passar por alto que Frege se concentra corretamente no que era essencial, sob seu ponto de vista, para a solução da verdadeira pergunta. Em 1891 Husserl, assim como toda a escola de Brentano nessa época, prende-se ao princípio de imanência e é, por conseguinte, sem mais, "psicologista" no sentido de Frege. ${ }^{31}$

\section{Conclusão}

Geralmente se apresenta a crítica de Frege ao psicologismo como se esta fosse uma via de mão única, isto é: Frege critica os psicologistas e os coloca em seu devido lugar, porém não recebe nenhuma reação dos mesmos. Como mostramos, não foi isto o que de fato ocorreu. Mas, se houve uma reação psicologista à crítica de Frege, ela esteve longe de não provocar efeito algum sobre ele.

As análises que desenvolvemos a partir de alguns textos fregeanos tornam plausível a ideia de que Frege tentou dar conta desta reação e correspondentemente aprofundar sua própria posição.

No parágrafo anterior nos expressamos com certo cuidado. Admitimos sem mais que nossa tese seja tal que nunca possa ser provada de modo definitivo. Como já ressaltamos, em nenhum lugar Frege toma explicitamente posição a respeito das objeções de Kerry por nós analisadas. Não obstante, os pontos de contato são chamativos. O material apresentado fornece motivos suficientes ao menos para uma suposição fundada de que a leitura da crítica psicologista de Kerry não permaneceu sem consequências para Frege, ainda que, talvez, ele nunca fosse consciente disso e, no momento da escrita dos trechos correspondente de GGA ou da Lógica de 1897, não tenha pensado em Kerry em absoluto. Em todo caso, isto é secundário e irrelevante. Relevante é atentar para uma possível influência negativa por esta abrir uma perspectiva sobre a qual até agora não se chamou a atenção: a réplica de Kerry à crítica de Frege ao psicologismo é digna

\footnotetext{
${ }^{31}$ „Worin alle Gegenstände - wirkliche und mögliche, reale und nicht reale, physische und psychische usw. übereinkommen, ist nur dies, dass sie Vorstellungsinhalte sind oder durch Vorstellungsinhalte in unserem Bewusstsein vertreten werden." PhA, p.80.
} 
de nota tanto do ponto de vista sistemático, quanto histórico-filosófico, devendo este a sua importância àquele.

O psicologismo figura como causa perdida, tanto que não se presta mais atenção ao fato de que não houve meramente uma crítica ao psicologismo, senão, propriamente, uma polêmica em torno ao mesmo, onde argumentos e contra-argumentos foram lançados uns contra outros. O que realmente aconteceu não foi simplesmente que os psicologistas receberam a crítica dos anti-psicologistas sem reagirem a esta; tampouco que os antipsicologistas criticaram um opositor a cuja reação não deram atenção.

A reconstrução da polêmica em torno ao psicologismo é ainda hoje uma tarefa em aberto. ${ }^{32}$ Dita polêmica começa de fato já com o surgimento do realismo lógico de Bolzano, como põe em evidência a troca de cartas entre Bolzano e Exner. ${ }^{33}$ Frente à asserção da existência de algo objetivo em-si por Bolzano, Exner opõe a questão crucial de como é possível que algo real, como o sujeito psíquico, possa apreender algo a princípio irreal. Com variações, esta questão reparece no diálogo entre Natorp e Cohen, mas também nos "Prolegômenos" de Husserl, assim como na crítica que Palágyi e Natorp dirigem a esta obra. Com outros acentos, mas com um núcleo similar, se deixa reconstruir uma intensa discussão entre Lipps, Wundt e Sigwart. É nesse contexto que devemos considerar a reação de Kerry a Frege. Ela é um momento de uma longa história. $\mathrm{O}$ ataque de Kerry a Frege não foi uma curiosidade, senão mais uma expressão de uma estratégia argumentativa muito difundida entre os psicologistas.

Tanto Exner quanto Kerry constroem sua réplica sob a pressuposição do princípio de imanência. No entanto, para além desta concordância, há também diferenças entre ambos. $\mathrm{O}$ realista lógico não pode evitar a questão de como o sujeito tem acesso ao objetivo. Uma vez admitido este ponto de partida, pode-se prosseguir de diversas maneiras. Para mostrá-lo, retomemos um raciocínio já exposto (4.2.) sob outra perspectiva.

a. De um lado, pode-se objetar ao antipsicologismo em geral que, enquanto este não fornece nenhuma explicação da relação entre o subjetivo e o objetivo, comete uma falta inaceitável. De certo modo é este o caso na já mencionada reação de Natorp ou Palágyi aos "Prolegômenos" de Husserl.

b. Colocamo-nos já em outro nível, se adicionamos que o antipsicologismo não só de fato não leva em conta a relação entre o subjetivo e o objetivo, senão que não pode fazê-lo e, portanto, está diante de

\footnotetext{
${ }^{32}$ Algum trabalho parcial a este respeito já foi fornecido por Kusch e Carl.

${ }^{33}$ Ver do autor "Platonismo e intencionalidad. A propósito de Bernard Bolzano".
} 
uma dificuldade de princípio. Isto pode ser precisado, por sua vez, de diferentes modos. É exatamente isso o que acontece em Exner e Kerry.

b1. No seu núcleo básico, presente nas considerações de Exner, o problema consiste em que há um abismo absoluto entre a realidade (Wirklichkeit) e a irrealidade (Unwirklichkeit).

b2. Em Kerry a situação é mais refinada. Ele não aponta propriamente para uma dificuldade insolúvel, mas para uma contradição inevitável, a qual, em última instancia, consiste em que o realismo lógico, que pretende negar o método psicológico, não consegue prescindir do mesmo.

Reflexões como as aqui apresentadas são importantes para fixar o papel de Frege na polêmica do psicologismo e, desta forma, conceber a peculiaridade da sua posição. Comparemos, por exemplo, a polêmica Kerry-Frege com a polêmica Exner-Bolzano. $\mathrm{O}$ que se diz na leitura standard acerca da posição de Frege vale, em realidade, para a de Bolzano, na qual estão manifestos todos os elementos que são atribuídos a Frege. A reação de Frege a Kerry é, porém, muito diferente da reação de Bolzano a Exner. Se, em princípio, poder-se-ia afirmar que ambos remetem o problema da apreensão à psicologia naturalística, isto acontece em Bolzano no marco de uma aceitação inquestionada da concepção de sujeito desta psicologia (associacionista e não-intencional), enquanto em Frege conduz a uma reformulação radical de tal concepção de subjetividade (intencional e não teórico-representacional (vorstellungstheoretisch)). $\mathrm{O}$ fato de que Frege não dispõe de uma "teoria da constituição" não deve ser confundido com o fato, totalmente diferente, de que Frege não tenha nada a dizer a respeito da subjetividade. Pelo contrario, é justamente o dispor de uma clara ideia de subjetividade, diferente da psicologista e inovadora no contexto da filosofia alemã da segunda metade do século XIX, o que o leva a rechaçar o problema da constituição e a reformulá-lo.

\section{Bibliografia:}

BAKER, G. P., HACKER, P. M. S. “Frege's Antipsychologism”. In: NOTTURNO, M. (org.). Perspectives on Psychologism. Leiden - New York - Köbenhavn: Köln, E. J. Brill, 1989. pp. 75-127.

CARL, Wolfgang. Frege's Theory of sense and reference. Its originis and Scope, Cambridge: Cambridge University Press, 1994.

FREGE, Gottlob. Begriffsschrift. Eine der arithmetischen nachgebildeten Formelsprache des reinen Denkens, in: Begriffsschrift und andere Aufsätze. 2da. ed. Ignacio Angelelli (ed.). Darmstadt, Wissenschaftliche Buchgesellschaft, 1971. págs. 1-88. pág. IX (Begr). 
. Die Grundlagen der Arithmetik. Eine logisch mathematische Untersuchung über den Begriff der Zahl, Hamburg: Meiner, 1988 (GA).

. Grundgesetze der Arithmetik, Jena: Pohl, 1893 (GGA).

. Logik (1897). In: GABRIEL, Gottfried (org.). Schriften zur Logik und Sprachphilosophie. Aus dem Nachlass, Hamburg: Meiner, 1980. 3. Aufl. (L(1897)).

. Der Gedanke. In: Logische Untersuchungen, Göttingen: Vandenhoeck und Ruprecht, $1986(\mathrm{G})$.

. Besprechung Husserl's Philosophie der Arithmetik, Zeitschrift für Philosophie und philosophische Kritik, NF. 103, 313-332, 1894 (BH).

Begriff und Gegenstand, In: PATZIG, G. (org.) Funktion, Begriff, Bedeutung, Göttingen: Vandenhoeck und Ruprecht, 1966 (BG).

GONZÁLES PORTA, Mario Ariel. "La cuestión noética en Frege, su concepto de intencionalidad y su influencia sobre Husserl", Thémata. Revista de Filosofia, XXIV, 83-114, 2000.

. "Platonismo e intencionalidade A propósito de Bernhard Bolzano", Sintese (nova fase): Primeira parte: 29, no. 94, 251-275, 2002; Segunda parte: 30, no. 96, 85-106, 2003.

. "Frege y Natorp: platonismos, psicologismos y teorías de la subjetividad", O que nos faz pensar, 20, 163-184, 2006.

. "Un análisis del opúsculo de Kasimir Twardowsky 'Inhalt und Gegenstand' en la perspectiva de su significación para la escuela de Brentano", Sintese. Revista de Filosofia, 34, no. 109, 261-282, 2007.

Aurora, 21, 545-568, 2009.

"Es el psicologismo refutable según Frege?" Revista de Filosofia 130-154, 2009.

. “A crítica de Frege ao idealismo em 'Der Gedanke'”. Veritas, 54,

66,2010 .

. "Psicologismo e idealismo em Frege e Husserl", Síntese, 37, 57-

publicado).

. "La evolución de la critica fregueana al psicologismo" (a ser ser publicado).

. "O desenvolvimento da critica de Husserl ao psicologismo" (a

$\overline{\text { (a ser publicado). }}$.

"La "Lógica" fregueana de 1897 y su réplica al psicologismo"

HUSSERL, E. Philosophie der Arithmetik, Hamburg: Meiner, 1992 (PhA).

KERRY, Benno. Über Anschauung und ihre psychische Verarbeitung. Vierter Artikel Vierteljahresschrift für wissenschaftliche Philosophie, 11, 249-307, 1887.

KUSCH, Martin. Psychologismus. A case study in the Sociology of philosophical Knowledge, London: Routledge, 1995. 
MOHANTY, J. N. "Psychologism” In: NOTTURNO, Mark. A. (org.). Perspectives on Psychologism. Leiden/New York/Kobenhavn/Köln: E. J. Brill, 1989. pp. 1-10.

. "The concept of 'Psychologism' in Frege and Husserl”, In: JACQUETTE, Dale. Philosophy, Psychology and Psychologism. Critical and Historical Readings on the Psychological Turn in Philosophy, Dordrecht/Boston/London: Kluwer Academic Publishers, 2003. pp.113-130.

PECHKAUS, Volker. "Benno Kerry. Beiträge zu seiner Biographie". History and Philosophie of Logik, 15, 1994, p. 1-8.

PICARDI, Eva. "Kerry und Frege über Begriff und Gegenstand", History and Philosophy of Logik, 15 (1994) pp. 9-32.

TWARDOWSKY, Kasimir. Über Inhalt und Gegenstand. Viena, 1894.

Endereço do Autor:

Rua Anastácio de Souza Pinto, 333 ap.12

Freguesia do Ó

02926-030 São Paulo - SP

mariopor@pucsp.br 